\title{
Complications of obesity in children and adolescents during covid-19 pandemic: A narrative review
}

\section{Complicaciones de la obesidad en niños y adolescentes durante la pandemia de COVID-19: Una revisión narrativa}

\begin{abstract}
Background: Obesity in children and adolescents has increased exponentially around the world. Furthermore, the COVID-19 pandemic has led to a higher pediatric obesity rate. The excess adipose tissue generates a dysregulation of adiponectin, ghrelin, and leptin, among others. Metabolic alterations can develop cardiovascular disease, dyslipidemias, arterial hypertension, type 2 diabetes mellitus, nonalcoholic fatty liver disease, sleep disorders, and higher risk of COVID-19 severity. Obesity has different therapeutic approaches such as behavioral weight loss programs, pharmacologic treatments, and surgical procedures. Therefore, timely diagnosis and treatment are important to decrease the mortality in obesity among pediatric population.
\end{abstract}

Keywords: Adolescents; Children; Complications; Obesity; COVID-19 (Source: DeCS-BIREME).

\section{RESUMEN}

Introducción: La obesidad en niños y adolescentes ha aumentado exponencialmente en todo el mundo. Asimismo, la pandemia del coronavirus (COVID-19) ha conducido a una mayor tasa de obesidad pediátrica. El exceso de tejido adiposo genera una desregulación de hormonas como adiponectina, ghrelina y leptina, entre otras. Las alteraciones metabólicas pueden ocasionar enfermedad cardiovascular, dislipidemias, hipertensión arterial, diabetes mellitus tipo 2 , enfermedad del hígado graso no alcohólico, trastornos del sueño y mayor riesgo de COVID-19 severo. La obesidad tiene diferentes enfoques terapéuticos, como programas conductuales de pérdida de peso, tratamientos farmacológicos y procedimientos quirúrgicos. De esta manera, el diagnóstico y el tratamiento oportuno es importante para disminuir la mortalidad asociada a la obesidad en la población pediátrica.

Palabras Clave: Adolescentes, niños, complicaciones, obesidad, COVID-19. (Fuente: DeCS-BIREME).

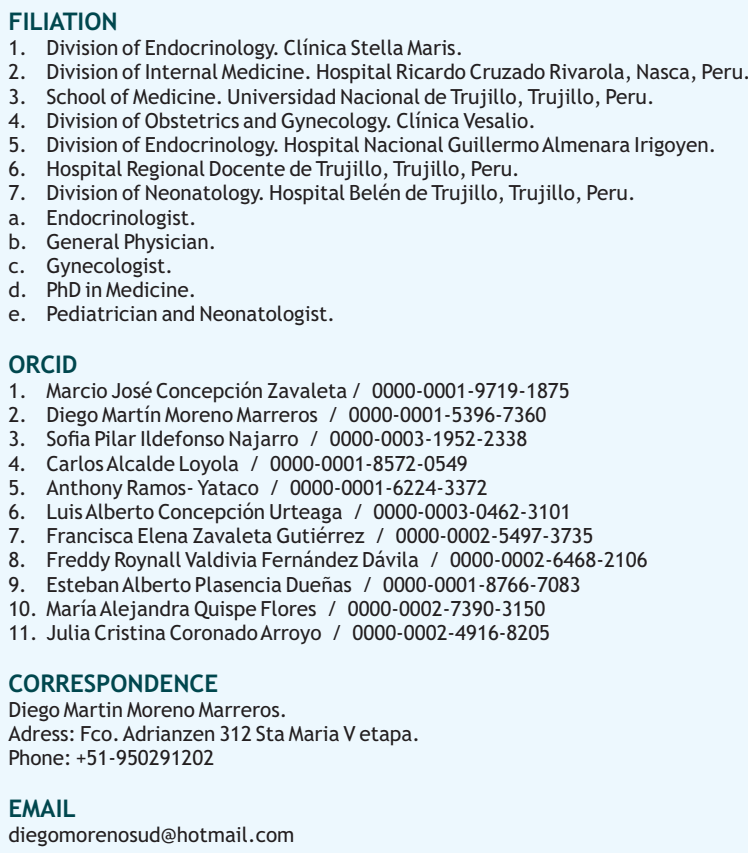

The authors declare that there is no conflict of interest that could be perceived as prejudicing the impartiality of the research reported.

FINANCING

Self-financing.

\section{PEER REVIEW}

Received: $30 / 05 / 2021$

Accepted: $24 / 08 / 2021$

\section{HOW TO CITE}

Concepción-Zavaleta, M., Ramos-Yataco, A., Alcalde-Loyola, C., Moreno-Marreros, D., Coronado-Arroyo, J., Ildefonso-Najarro, S., Quispe-Flores, M., Plasencia-Dueñas, E., Concepción-Urteaga, L., Zavaleta-Gutiérrez, F., \& Fernández-Dávila, F. Complicaciones de la obesidad en niños y adolescentes durante la pandemia de COVID-19: Una revisión narrativa. Revista Del Cuerpo Médico Hospital Nacional Almanzor Aguinaga Asenjo, 2021, 14(Sup1), 55 61. https://doi.org/10.35434/rcmhnaaa.2021.14Sup1.1175

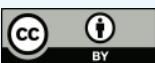

This work is under a Licencia Creative Commons Atribución 4.0 Internacional. Printer Version: ISSN: 2225-5109 Electronic Version: ISSN: 2227-4731 Cross Ref. DOI: $10.35434 /$ rcmhnaaa OJS: https://cmhnaaa.org.pe/ojs 


\section{INTRODUCTION}

Obesity is a public health problem. Over the years, its prevalence and incidence have been progressively increasing worldwide $^{(1,2)}$. The global prevalence of obesity has increased at an alarming rate in children and adolescents from $0.7 \%$ to $5.6 \%$ in boys and from $0.9 \%$ to $7.8 \%$ in girls between 1975 and $2016^{(2)}$.

The nutritional status classifications in children and adolescents can be classified according to body mass index (BMI) (Table 1). Although BMI provides a good measure of body fat in adults, children body fat varies according to age and gender. As such, fixed levels of BMI provide inaccurate comparisons $^{(3)}$.

Table 1. Weight categories for youth (2-18 years) according to body mass index (BMI).

\begin{tabular}{ll} 
NUTRITIONAL STATUS & \\
Underweight & $\mathrm{BMI}<5^{\text {th }}$ percentile for age \\
Normal weight & $\mathrm{BMI} \geq 5^{\text {th }}$ to $<85^{\text {th }}$ percentile for age \\
Overweight & $\mathrm{BMI} \geq 85^{\text {th }}$ to $<95^{\text {th }}$ percentile for age \\
Obesity & $\mathrm{BMI} \geq 95^{\text {th }}$ \\
Severe obesity & $\mathrm{BMI} \geq 120 \%$ of the $95^{\text {th }}$ percentile or a $\mathrm{BMI} \geq 35 \mathrm{~kg} / \mathrm{m}^{2}$ \\
\hline
\end{tabular}

Additionally, according to the WHO, in children under 5 years of age, overweight can be diagnosed when the weight/height ratio is greater than 2 standard deviation and obesity when the weight/height ratio is greater than 3 standard deviations. In Peru, during the last decade, the prevalence of overweight and obesity in children under 5 years of age, after having reached their minimum values in $2016(6.1 \%$ and $1.5 \%$ respectively), have been increasing progressively to $6.7 \%$ overweight and $2.1 \%$ obesity for the second quarter of 2021 , according to the Sistema de Información Del Estado Nutricional (SIEN) of the Instituto Nacional de Salud (INS) ${ }^{(1)}$.

Obesity is associated with multiple comorbidities ${ }^{(2)}$, including cardiovascular, dermatologic, endocrine, gastrointestinal, neurologic, orthopedic, psychosocial, and pulmonary comorbidities (Table 2).

Table 2. Comorbidities of obesity in children and adolescents

\begin{tabular}{|c|c|}
\hline Cardiovascular & $\begin{array}{l}\text { Hypertension, dyslipidemia, abnormal cardiac structure and function } \\
\text { and adult cardiovascular disease }\end{array}$ \\
\hline Dermatology & $\begin{array}{l}\text { Acanthosis nigricans, striae, intertrigo, furunculosis, hydradenitis } \\
\text { suppurativa }\end{array}$ \\
\hline Endocrine & $\begin{array}{l}\text { Prediabetes, diabetes mellitus, metabolic syndrome, } \\
\text { hyperandrogenism and polycystic ovary syndrome, growth and } \\
\text { puberty }\end{array}$ \\
\hline Gastrointestinal & Nonalcoholic fatty liver disease, cholelitiasis \\
\hline Neurologic & Idiopathic intracranial hypertension \\
\hline Orthopedic & Slipped capital femoral epiphysis, fractures, genu varus or valgus \\
\hline Psychosocial & $\begin{array}{l}\text { Social isolation, anxiety, depression, distorted peer relationships, } \\
\text { disorder eating patterns }\end{array}$ \\
\hline Pulmonary & Asthma, obstructive sleep apnea, obesity hypoventilation syndrome \\
\hline
\end{tabular}

\section{PATHOPHYSIOLOGY}

Obesity in children has a complex etiology that originates from environmental factors (sedentary lifestyle, high-calorie diets) in modern societies ${ }^{(2)}$. Nonetheless, genetic factors may play an important role in its pathogenesis. However, the role of genes in obesity may be modest, and obesity predisposition may result from a combination of specific genes. More studies need to be conducted to fully understand the gene-environment interaction and epigenetics mechanism related to obesity ${ }^{(4)}$.

Obesity substantially increases the risk of metabolic and cardiovascular diseases such as type 2 diabetes mellitus, fatty liver disease, hypertension, myocardial infarction and stroke ${ }^{(2)}$. The increase in adipose tissue influences the pathogenesis of atherosclerosis. Adipose tissue includes two types, namely, white adipose tissue (WAT) and brown adipose tissue.

WAT secretes peptides and proteins that play an important role in obesity, insulin resistance, immune functions, atherosclerosis, and CVD. Among them, adiponectin stands out, that is expressed at high levels in lean and healthy people and is deregulated in obesity ${ }^{(5)}$. Molecular studies have reported that adiponectin could modulate atherogenic mechanisms involved in endothelial cells (nitric oxide production, mitigation of pro-atherogenic mediators, stabilization of the coronary plaque, and arterial vasodilation). Likewise, it is known that perivascular adipose tissue, particularly in obese people, promotes local inflammation and deterioration of endothelial function, providing a link between adipose tissue and vascular disease ${ }^{(6)}$.

On the other hand, obesity is considered an inflammatory state, in which an increase in adipose tissue and a reduction in adiponectin levels occurs. Its unbalance perpetuates inflammation, leading to cardiometabolic alterations. Furthermore, obesity leads to insulin resistance and endothelial dysfunction due to the formation of proinflammatory cytokine and lipid metabolism products ${ }^{(6)}$. Endothelial dysfunction has been associated with cardiovascular conditions, such as atherosclerosis, hypertension $(\mathrm{HT})$, hyperlipidemia, and insulin resistance ${ }^{(5)}$.

Obesity is associated with elevated levels of leptin and greater release of reactive oxygen species from the endoplasmic reticulum, generating less insulin secretion and sensitivity. Leptin influences the production of nitric oxide and activates the sympathetic system, causing sodium retention, systemic vasoconstriction, and blood pressure elevation $^{(7)}$.

\section{OBESITY AND COVID-19}

The COVID-19 pandemic led to different policies to contain the virus, such as lock-downs around the world, resulting in physical activity and changes in dietary behavior among children and adolescents. In addition, the reduction in social interaction causes isolation and a feeling of loneliness among children, leading to changes in emotional eating ${ }^{(8)}$. 
As a result of this, children gained weight, and the prevalence of childhood obesity increased in different countries $^{(8)}$. In the Unites States, the prevalence increased more than $15 \%{ }^{(9)}$. In China, the BMI increased significantly in adolescents and young adults (15-17 years), while the prevalence of obesity increased from $10.5 \%$ to $12.9 \%$ (I < 0.001 ) in these age groups ${ }^{(10)}$. A new term, "covibesity," was introduced to describe the worsening of obesity rates due to confinements ${ }^{(11)}$.

The three main risk factors that link obesity with COVID-19 demonstrated in adults that are also present in children and adolescents are chronic subclinical inflammation, impaired immune response, and underlying cardiorespiratory diseases ${ }^{(12)}$. Obesity is linked to a pro-inflammatory state induced by the production of cytokines such as interleukin-6 (IL-6) and C-reactive protein. These cytokines have been positively correlated with COVID-19 severity, and their higher levels in obese pediatric population may be related to increased susceptibility to severe infection ${ }^{(13)}$.

\section{OBESITY AND CARDIOVASCULAR RISK}

Both obesity and atherosclerosis are considered chronic inflammatory conditions, in which the activation of nonspecific and immune-adaptive processes plays a significant role $\mathrm{e}^{(14)}$. The pathogenesis of obesity and atherosclerosis has several common factors. In both cases, the oxidized LDL particles and free fatty acids activate the inflammatory process and trigger the disease. Inflammation is responsible for all steps toward atherosclerosis, from the onset of endothelial dysfunction to atherosclerotic plaques, causing complications, and is related to obesity, insulin resistance, and type 2 diabetes (T2DM) ${ }^{(15)}$.

Fat tissue releases adipocytokines, which induce insulin resistance, endothelial dysfunction, hypercoagulability, and systemic inflammation, facilitating the atherosclerotic process. In visceral obesity, inflammatory adipocytokines (e.g., TNF-a, IL-6, MCP-1, leptin, and resistin) rise to higher levels. Furthermore, increased $\mathrm{C}$-reactive protein level is associated with an increased risk of myocardial infarction, peripheral vascular disease, and diabetes mellitus ${ }^{(16)}$.

Likewise, obesity leads to heart failure through several indirect mechanisms. Excess weight leads to hemodynamic changes: an increase in cardiac output and blood pressure has been observed, and an increase in BMI of $5 \mathrm{~kg} / \mathrm{m}^{2}$ generates a $5 \mathrm{mmHg}$ increase in systolic blood pressure. On the one hand, it is related to the activation of the renin-angiotensin -aldosterone system and the increased activity of the sympathetic nervous system ${ }^{(7)}$.

Obesity increases the aldosterone level and expression of the mineralocorticoid receptor, promoting interstitial fibrosis, platelet aggregation, and endothelial dysfunction in the heart. Increased blood volume facilitates venous return flow, which improves preload, causing increased ventricular wall tension and ultimately leading to ventricular dilation. The inflammatory cytokines (TNF-a, IL-1, IL-6, IL-8), which are increased in obese people, also play an important role in heart failure development. The effect of leptin and adiponectin on the metabolism and extracellular matrix can contribute directly to the myocardial transformation. The accumulation of triglycerides in the heart muscle can be observed regularly in obese patients and facilitates the generation of toxic metabolites (ceramide and diacylglycerol), causing apoptosis of cardiomyocytes ${ }^{(16)}$.

Besides, obesity has been shown to increase the probability of heart failure, not only by itself but also through associated medical comorbidities (Figure 1).

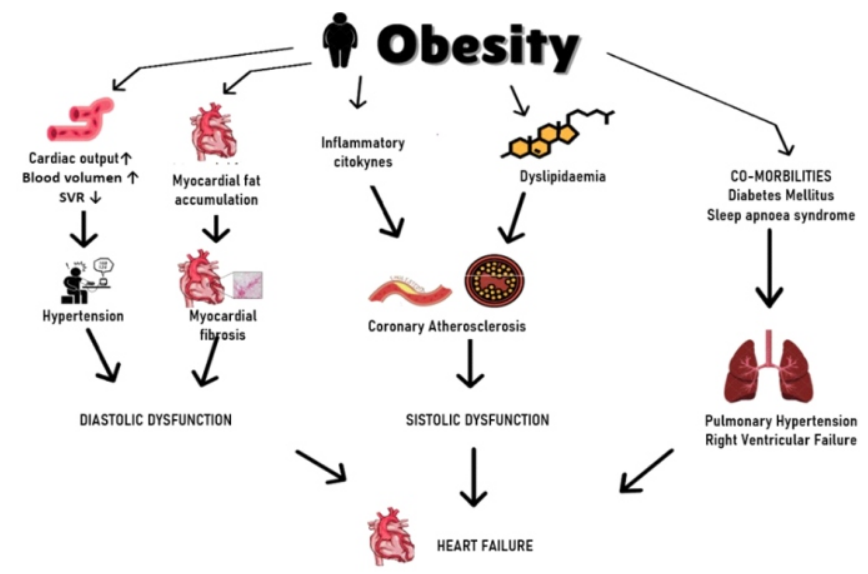

Figure 1.

Impact of obesity on the development and worsening of heart failure.

Several studies have shown the relationship between obesity and atrial fibrillation (Figure 2). Obese patients have a 1.52 times higher risk of developing atrial fibrillation compared to the normal weight population. Likewise, an increased risk of sudden cardiac death, stroke, thromboembolic complications, and heart failure exists in patients with atrial fibrillation. Moreover, atrial fibrillation lengthens the hospitalization time and worsens quality of life and physical capacity $^{(17)}$.

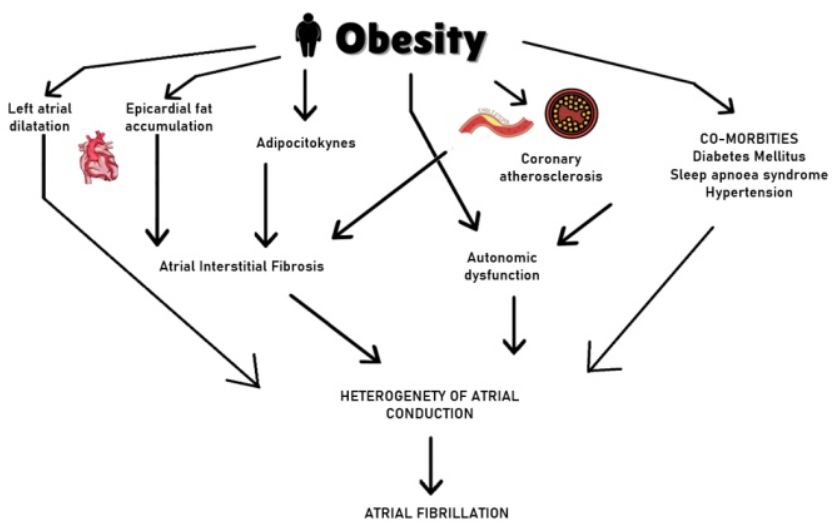

Figure 2.

Association of obesity and the development of cardiac arrhythmias.

Morbid obesity (defined as $\mathrm{BMI}>35 \mathrm{~kg} / \mathrm{m}^{2}$ ) potentially causes a wide range of alterations in heart performance, including changes in cardiac hemodynamics, left ventricular function, and morphology ${ }^{(18)}$ (Table 3). 
Table 3. Impact of obesity on hemodynamics and heart morphology.

\begin{tabular}{ll}
\hline HEMODYNAMICS & $\begin{array}{l}\uparrow \text { blood volume, stroke volume/work } \\
\uparrow \text { arterial pressure, LV wall stress } \\
\text { Pulmonary artery hypertension }\end{array}$ \\
& LV concentric remodeling, hypertrophy \\
CARDIAC STRUCTURE & Left atrial enlargement \\
& RV hypertrophy \\
CARDIAC FUNCTION & $\begin{array}{l}\text { LV diastolic or systolic dysfunction } \\
\text { RV failure }\end{array}$ \\
\hline
\end{tabular}

RV: Right ventricle, LV: Left ventricle.

Screening for cardiometabolic risk factors (HT, dyslipidemia, T2DM) should be undertaken in all children with obesity. Specific coronary risk scores, such as the Framingham risk score, are well established for clinical risk stratification in adults; however, no similar risk stratification tools are available in children ${ }^{(19)}$.

A risk score developed from the PDAY (Prediction of coronary artery calcium in young adults using the pathobiological Determinants of Atherosclerosis in Youth) study has been used in pediatric, using the autopsy findings in subjects 15-34 years of age and coronary heart disease risk factors (gender, age, serum lipoprotein concentrations, smoking, HT, obesity, and hyperglycemia) to estimate the probability of advanced atherosclerotic lesions in the coronary arteries. However, more studies are needed to assess the utility of this risk score $^{(20)}$.

\section{SLEEP DISORDERS AND OBESITY}

Sleep restriction seems to be related to our modern way of life. People who sleep little can have difficulties in maintaining a healthy lifestyle in the current environment since it promotes excessive consumption of food and sedentary behaviors. Moreover, there is strong evidence to support that sleep reduction is a contributor to obesity in all age groups of the pediatric population ${ }^{(21)}$. Increased food intake seems to be the main explanation for why a lack of sleep can lead to weight gain ${ }^{(22)}$.

Chaput JP et al. hypothesized an interesting theory to explain the relationship between short sleep duration and obesity. For weight gain to occur, there must be an imbalance between energy intake and expenditure. The energy intake is determined by eating food, and the energy expenditure is determined by physical activity. Both factors would be altered by a decrease in sleep, the consequence of which would be weight gain ${ }^{(22)}$. (Figure 3 ). However, this author does not define exactly the number of hours that would be the threshold to define short sleep, which would have this effect (weight gain). Subsequent studies clearly show that sleeping for less than $6 \mathrm{~h}$ is considered a cutoff point for this particular effect and other harmful effects on health ${ }^{(23)}$.

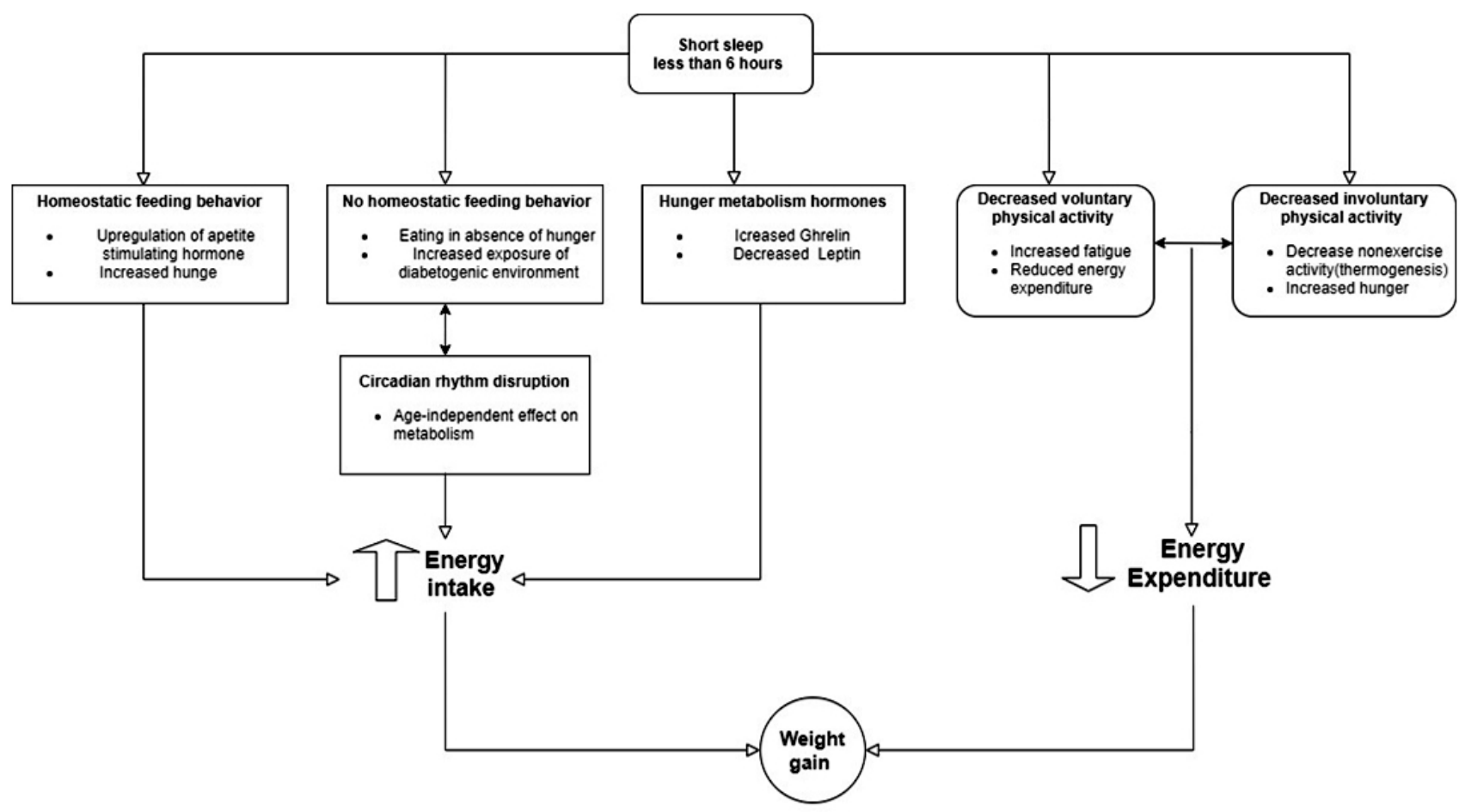

Figure 3.

Relation between short sleep and obesity. 
Obstructive sleep apnea (OSA) is an obesity-related complication that has recently gained attention. It is defined as a breathing disorder during sleep in which partial or complete airway obstruction disrupts ventilation. The prevalence of OSA varies between $1 \%$ and $5 \%$ in general pediatric population; however, among obese children and adolescent, the prevalence of OSA is estimated to range between $20 \%$ and $61 \%$. OSA in obese children is associated with cardiovascular complications such as right and left ventricular dysfunction, besides increased systolic blood pressure $^{(24)}$. All this information suggests that OSA may have a negative impact on long-term cardiovascular health.

\section{NAFLD AND OBESITY}

Nonalcoholic fatty liver disease (NAFLD) is directly linked to obesity and has become a major cause of chronic liver disease among children and adolescent with obesity. Two hypotheses have been put forward to explain the pathophysiology of NAFLD. First, obesity-related hyperinsulinemia and insulin resistance lead to liver steatosis ${ }^{(25)}$. Second, the oxidative stress by reactive oxygen species (ROS) may cause hepatocellular damage inhibiting mitochondrial respiratory chain enzymes. Furthermore, ROS may cause lipid membrane peroxidation, apoptosis of hepatocytes induced by Fas ligand, and cytokine production, perpetuating hepatocellular injury and fibrosis ${ }^{(26)}$.

NAFLD has been recognized as an independent risk factor for CVD; however, the association is still debated in pediatric population. This association has not been fully understood yet, but increased visceral fat tissue and insulin resistance may be important contributing factors ${ }^{(27)}$. NAFLD is part of the metabolic syndrome, which is an atherogenic state. Atherosclerosis has been shown to begin in pediatric age ${ }^{(28)}$. To the best of our knowledge, the mechanism by which NAFLD may lead to atherogenesis is not elucidated, but increased visceral adipose tissue expressed by particularly periaortic fat thickness, altered lipoprotein metabolism, insulin resistance, and inflammatory cytokines released by NAFLD may play a significant role. (Figure 4)

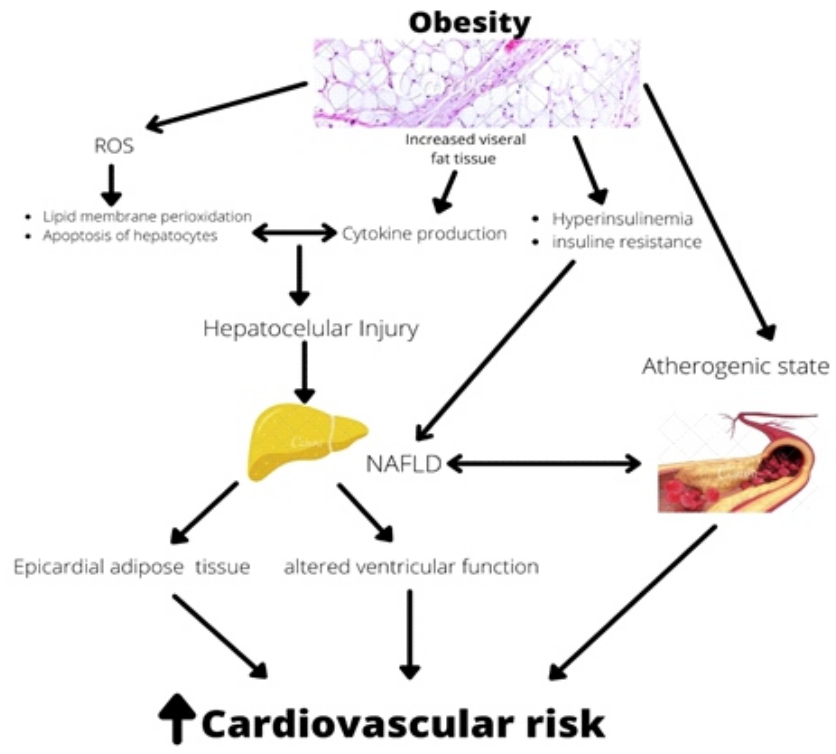

Figure 4.

Relationship between obesity and non-alcoholic fatty liver disease.

\section{TREATMENT OF OBESITY IN CHILDREN AND ADOLESCENTS}

The three main treatment approaches for pediatric obesity are diet and lifestyle modification, pharmacological interventions, and surgical management.

\section{A. BEHAVIORAL INTERVENTIONS FOR WEIGHT LOSS}

Successful weight loss can be improved by incorporating behavioral strategies ${ }^{(29)}$.

Examples of well-proven behavioral weight loss programs designed to reduce body weight include the Diabetes Prevention Project, the Look AHEAD Study for Adults, and family-based behavioral weight loss programs (FBT) for children $^{(29)}$. Systematic reviews in this area show that adults who participate in behavioral weight loss (BWL) programs of 12-26 sessions lose approximately $6 \%$ of their body weight ${ }^{(30)}$, while children who participate in at least ${ }^{(26)} \mathrm{BWL}$ sessions lose $0.2 \mathrm{ZBMl}^{(31)}$, both clinically significant weight losses associated with multiple improvements in health.

The trials used different intervention methods, such as group, individual, and mixed. Group interventions consisted of classroom-style sessions that lasted from 1 to $2 \mathrm{~h}$ and ranged from eight group sessions over 2.5 months to weekly group sessions over 1 year. Most individualbased interventions provided individual counseling sessions, with or without ongoing telephone support, with a median number of sessions in the first year of $12^{(32)}$. Mixed-based interventions included the same number of group and individual counseling sessions. Most of these interventions were carried out for more than 1 year and involved more than 12 sessions (median, 23 sessions in total in the first year). In the technology-based interventions, web-based intervention modules, webbased self-monitoring, mobile phone-based text messages, smartphone apps, social media platforms, or DVD learning were included. In addition, in most of these behavioral interventions, self-control was promoted by recording daily dietary intake ${ }^{(33)}$. Using websites that provided real-time feedback on the total calories consumed for the day based on the foods and portion sizes recorded, the remaining calories can help achieve the participant's personal daily goal ${ }^{(34)}$.

Most of these behavioral interventions were designed to help participants achieve or maintain a weight loss of $5 \%-10 \%$ or more through a combination of dietary changes and increased physical activity ${ }^{(29)}$.

\section{B. PHARMACOLOGICAL INTERVENTION}

The 2017 Endocrine Society Clinical Practice Guidelines recommend pharmacotherapy for children or adolescents after a formal program of intensive lifestyle modification has failed ${ }^{(35)}$.

Orlistat is the only FDA (US Food and Drug Administration)-approved weight loss medication for use in children $\geq 12$ years who are overweight/obese. This lipase inhibitor is associated with $1-2 \mathrm{~kg}$ weight loss in adolescents. It has been associated with modest improvement in diastolic blood pressure and a marker of endothelial function (flow-mediated dilation), but its cumulative effect on reducing cardiometabolic disease remains unknown ${ }^{(35)}$. 
Table 4. Criteria for bariatric surgery in adolescents.

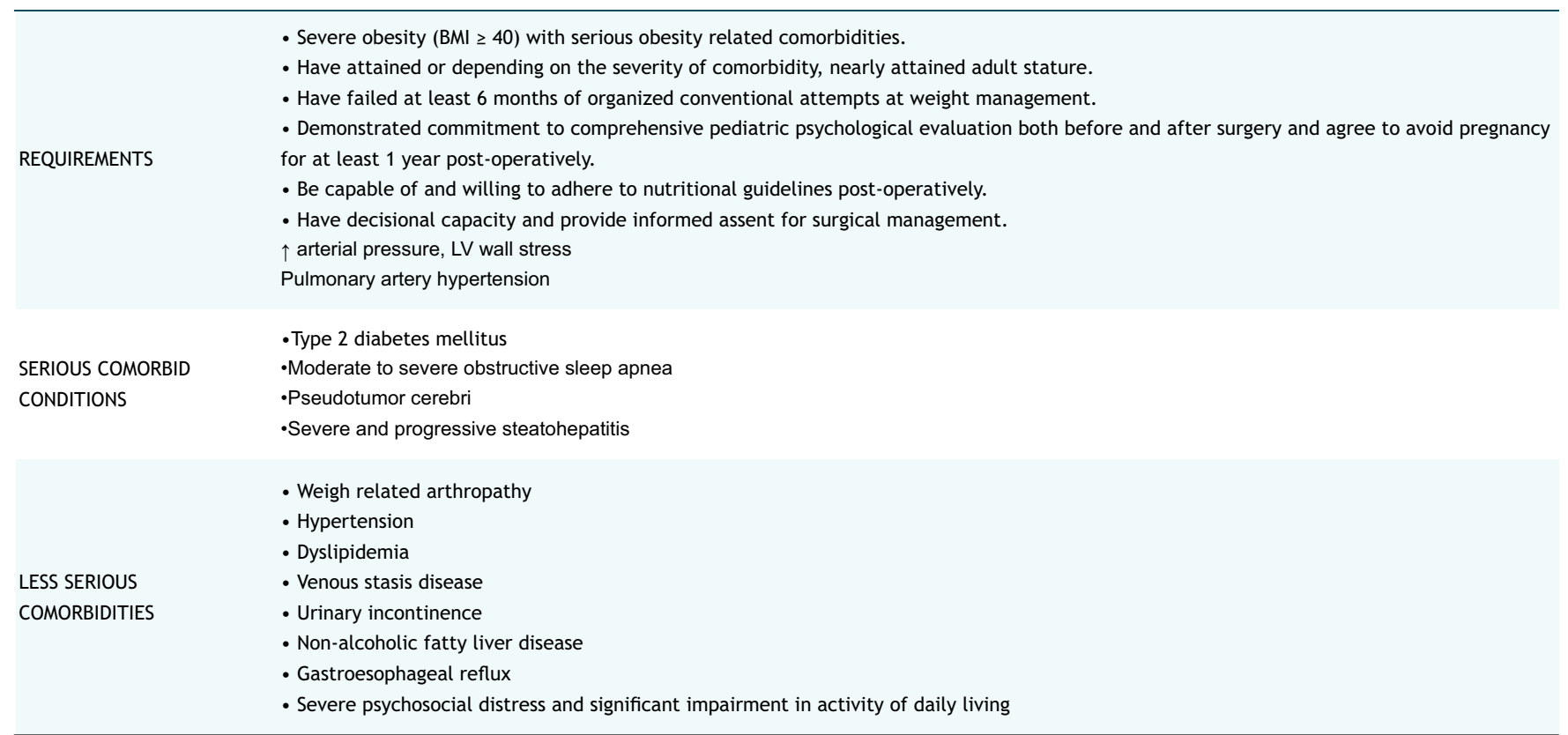

Metformin is the most common agent evaluated for the treatment of obesity in children. Randomized trials of metformin have demonstrated modest weight loss (2-4 $\mathrm{kg}$ ) in youth with marked improvement in markers of insulin resistance. However, similar to studies conducted for orlistat, most metformin trials are $\leq 1$ year in duration, and the durable effect of these pharmacological agents on weight loss or cardiometabolic risk reduction requires further investigation $^{(36)}$.

\section{SURGICAL MANAGEMENT}

Bariatric surgery is a treatment option for obese adolescents. Three procedures are primarily used for adolescent bariatric surgery, namely, laparoscopic sleeve gastrectomy (LSG), laparoscopic adjustable gastric banding (LAGB), and Roux-en-Y gastric bypass (RYGB). Weight loss occurs due to a restrictive and malabsorptive component $^{(37)}$.

The International Pediatric Endosurgery Group recommends surgery in adolescents who have attained or almost attained adult stature with specific guidance ${ }^{(37)}$. (Table 4).

Due to the complex nature intervention, particularly at the vulnerable age of these patients, the use of multidisciplinary team has become well established as the gold standard of care necessary to provide a safe and efficient service.

The team members recommended by the American Society of Metabolic and Obesity Surgeon (ASMBS) includes an experienced bariatric surgeon; a pediatrician with a speciality in endocrinology and nutrition; a dietician with experience in pediatric obesity; and a psychiastrist or psychologist with specialty training in treating eating disorders and obesity in adolescents ${ }^{(38)}$.

Regarding the outcomes of the surgical management of obesity in this population, there are several studies carried out. In the Swedish Adolescent Morbid Obesity Surgery study, a prospective nationwide study, they performed laparoscopic RYGB in adolescents aged 13-18 years old. A significant lower BMI was observed postoperatively compared with age-matched medically managed controls. Moreover, cardiovascular risk factors substantially improved after surgery, including glucose tolerance, blood pressure, and plasma lipid concentration. All patients experienced T2DM remission ${ }^{(39)}$. The Follow-up of Adolescent Bariatric Surgery at 5 Plus Years (FABS 5+) investigated the outcomes of adolescent bariatric surgery 5-12 years after RYGB. In that study, mean baseline BMI was reduced postoperatively by $29 \%$. Furthermore, there were remission of T2DM and resolution rate of hypertension ${ }^{(40)}$.

\section{CONCLUSIONS}

- Obesity by itself, and its associated comorbidities, generates structural and functional alterations, increasing cardiovascular risk.

- The pathophysiological processes that link obesity with atherosclerosis and CVD imply a chronic inflammatory state.

- People with obesity without metabolic abnormalities have a higher risk of coronary artery disease and heart failure than metabolically healthy people of normal weight.

- Severe obesity in children and adolescents is associated with a higher incidence of HT, dyslipidemia, and impaired fasting glucose.

- Timely diagnosis and treatment of obesity is important to decrease the mortality among pediatric population. 


\section{REFERENCIAS BIBLIOGRÁFICAS}

1. Vigilancia Del Sistema De Información Del Estado Nutricional en EESS. Instituto Nacional de Salud. 2021 [cited 2021 Set 26]. Disponible en: https://web.ins.gob.pe/es/alimentacion-y-nutricion/vigilanciaalimentaria-y-nutricional/vigilancia-del-sistema-de-informaciondel-estado-nutricional-en-\%20EESS

2. Blüher M. Obesity: global epidemiology and pathogenesis. Nat Rev Endocrinol. 2019;15(5):288-298. http://dx.doi.org/10.1038/s41574019-0176-8

3. Durkin N, Desai AP. What Is the Evidence for Paediatric/Adolescent Bariatric Surgery? Curr Obes Rep. 2017;6(3):278-285. doi:10.1007/s13679-017-0277-4

4. Herrera BM, Keildson S, Lindgren CM. Genetics and epigenetics of obesity. Maturitas. 2011;69(1):41-49. doi: 10.1016/j.maturitas.2011.02.018

5. Oussaada SM, van Galen KA, Cooiman MI, Kleinendorst L, Hazebroek E, Van Haelst MM, et al. The pathogenesis of obesity. Metabolism. 2019; 92:26-36. doi: 10.1016/j.metabol.2018.12.012

6. Cercato C, Fonseca FA. Cardiovascular risk and obesity. Diabetol Metab Syndr. 2019;11(1):1-15. doi:10.1186/s13098-019-0468-0

7. Mendoza MF, Kachur SM, Lavie CJ. Hypertension in obesity. Curr Opin Cardiol. 2020;35(4):389-396. doi:10.1097/HCO.0000000000000749

8. Huizar MI, Arena R, Laddu DR. The global food syndemic: The impact of food insecurity, Malnutrition and obesity on the healthspan amid the COVID-19 pandemic. Prog Cardiovasc Dis. 2021; 64:105-107.

9. Dutta M. COVID-19 and Impact of School Closures on the Children of the United States; a Point of View with an Empirical Analysis. Social Sciences \& Humanities Open [Revista on-line] 2020 [Cited 2020 Nov 30]. Disponible en: https: / / ssrn.com/abstract $=3596096$

10. Yang S, Guo B, Ao L, Yang C, Zhang L, et al. Obesity and activity patterns before and during COVID-19 lockdown among youths in China. Clin Obes. 2020;10(6):e12416. doi: 10.1111/cob.12416

11. Khan MA, Moverley Smith JE. "Covibesity," a new pandemic. Obes Med. 2020; 19:100282. doi: 10.1016/j.obmed.2020.100282

12. Frühbeck G, Baker JL, Busetto L, Dicker D, Goossens GH, Halford JCG, et al. European Association for the Study of Obesity Position Statement on the Global COVID-19 Pandemic. Obes Facts. 2020;13(2):292-296. doi: 10.1159/000508082

13. Kruglikov IL, Scherer PE. The Role of Adipocytes and Adipocyte-Like Cells in the Severity of COVID-19 Infections. Obesity. 2020;28(7):1187-1190. doi:10.1002/oby.22856

14. Arkan MC, Hevener AL,Greten FR, Maeda S, Li ZW, Long JM, et al. IKKbeta links inflammation to obesity-induced insulin resistance. Nat. Med.2005 11(2), 191-198. doi: 10.1038/nm1185

15. Rocha VZ, Libby P. Obesity, inflammation, and atherosclerosis. Nat Rev Cardiol. 2009;6(6):399-409. doi:10.1038/nrcardio.2009.55

16. Csige I, Ujvárosy D, Szabó Z, Lorincz I, Paragh G, Harangi M, et al. The Impact of Obesity on the Cardiovascular System. J Diabetes Res. 2018;2018. doi:10.1155/2018/3407306

17. Goudis CA, Korantzopoulos P, Ntalas I V., Kallergis EM, Ketikoglou DG. Obesity and atrial fibrillation: A comprehensive review of the pathophysiological mechanisms and links. J Cardiol. 2015;66(5):361369. doi: $10.1016 /$ j.jjcc. 2015.04 .002

18. Albakri A. Obesity cardiomyopathy: a review of literature on clinical status and meta-analysis of diagnostic and clinical management. Med Clin Arch. 2018;2(3):1-13. doi:10.15761/mca.1000134

19. Bloetzer C, Bovet P, Suris JC, Simeoni U, Paradis G, Chiolero A. Screening for cardiovascular disease risk factors beginning in childhood. Public Health Rev. 2015;36(1):1-9. doi:10.1186/s40985015-0011-2

20. Gidding SS, MCMahan CA, McGill HC, Colangelo LA, Schreiner PJ, Williams OD, et al. Prediction of coronary artery calcium in young adults using the pathobiological determinants of atherosclerosis in youth (PDAY) risk score: The CARDIA study. Arch Intern Med. 2006;166(21):2341-2347. doi:10.1001/archinte.166.21.2341

21. Chaput JP. Is sleep deprivation a contributor to obesity in children? Eat Weight Disord. 2016;21(1):5-11. doi:10.1007/s40519-015-0233-9

22. Chaput JP, Klingenberg L, Sjödin A. Do all sedentary activities lead to weight gain: Sleep does not. Curr Opin Clin Nutr Metab Care.
2010;13(6):601-607. doi:10.1097/MCO.0b013e32833ef30e

23. Itani $\mathrm{O}$, Jike $M$, Watanabe N, Kaneita Y. Short sleep duration and health outcomes: a systematic review, meta-analysis, and metaregression. Sleep Med. 2017;32:246-256. doi: 10.1016/j.sleep.2016.08.006

24. Marcus CL, Brooks LJ, Draper KA, Gozal D, Ward SD, Sheldon SH, et al . Diagnosis and management of childhood obstructive sleep apnea syndrome. Pediatrics. 2012;130(3). doi:10.1542/peds.2012-1672

25. Marzuillo P, Grandone A, Perrone L, del Giudice EM. Understanding the pathophysiological mechanisms in the pediatric non-alcoholic fatty liver disease: The role of genetics. World J Hepatol. 2015;7(11):1439-1443. doi:10.4254/wjh. v7.i11.1439

26. Giorgio V, Prono F, Graziano F, Nobili V. Pediatric nonalcoholic fatty liver disease: old and new concepts on development, progression, metabolic insight and potential treatment targets. BMC Pediatr. 2013;13(1):1. doi:10.1186/1471-2431-13-40

27. Santoro N, Caprio S. Nonalcoholic fatty liver disease/nonalcoholic steatohepatitis in obese adolescents: A looming marker of cardiac dysfunction. Hepatology. 2014;59(2):372-374. doi:10.1002/hep. 26663

28. Stary HC. Lipid and macrophage accumulations in arteries of children and the development of atherosclerosis. Am J Clin Nutr. 2000;72(5 SUPPL.). doi:10.1093/ajcn/72.5.1297s

29. Wilfley DE, Stein RI, Saelens BE, Mockus DS, Matt G E, Hayden - Wade $\mathrm{HA}$, et al. Efficacy of Maintenance Treatment. J Am Med Assoc. 2007;298(14):1661-1673. doi: 10.1001/jama.298.14.1661

30. Moyer VA. Annals of Internal Medicine Clinical Guideline Services Task Force Recommendation Statement OF AND. Ann Intern Med. 2012;157(5):373-378.

31. O'Connor EA, Evans C V., Burda BU, Walsh ES, Eder M, Lozano P. Screening for obesity and intervention forweight management in children and adolescents evidence report and systematic review for the us preventive services task force. JAMA - J Am Med Assoc. 2017;317(23):2427-2444. doi:10.1001/jama.2017.0332

32. LeBlanc ES, Patnode CD, Webber EM, Redmond N, Rushkin M, O'Connor EA. Behavioral and pharmacotherapy weight loss interventions to prevent obesity-related morbidity and mortality in adults updated evidence report and systematic review for the US preventive services task force. JAMA - J Am Med Assoc. 2018;320(11):1172-1191. doi:10.1001/jama.2018.7777

33. Painter SL, Ahmed R, Hill JO,Kushner RF, Lindquist R, Brunning S, et al. What matters in weight loss? An in-depth analysis of selfmonitoring. J Med Internet Res. 2017;19(5):1-14. doi:10.2196/jmir.7457

34. Holzmann SL, Holzapfel C. A scientific overview of smartphone applications and electronic devices for weight management in adults. J Pers Med. 2019;9(2):31. doi:10.3390/jpm9020031

35. Chung S, Onuzuruike AU, Magge S. Cardiometabolic risk in obese children. Ann N Y Acad Sci. 2018;1411(1):166-183. doi: $10.1111 /$ nyas. 13602 . Cardiometabolic

36. Axon E, Atkinson G, Richter B,Metzendor MI, Baur L, Finer N, et al. Cochrane Library Cochrane Database of Systematic Reviews Drug interventions for the treatment of obesity in children and adolescents (Review). Published online 2020. doi: 10.1002/14651858.CD012436.www.cochranelibrary.com

37. Karasko D. Weight Loss in Adolescents After Bariatric Surgery: A Systematic Review. J Pediatr Heal Care. 2019;33(1):26-34. doi: 10.1016/j.pedhc.2018.05.010

38. Michalsky M, Reichard K, Inge T, Pratt J, Lenders C. ASMBS pediatric committee best practice guidelines. Surg Obes Relat Dis. 2012;8(1):1-7. doi: 10.1016/j.soard.2011.09.009

39. Olbers T, Beamish AJ, Gronowitz E,Flodmark C E, Dahlgren J, Bruze G, et al. Laparoscopic Roux-en-Y gastric bypass in adolescents with severe obesity (AMOS): a prospective, 5-year, Swedish nationwide study. Lancet Diabetes Endocrinol. 2017;5(3):174-183. doi:10.1016/S2213-8587(16)30424-7

40. Inge TH, Jenkins TM, Xanthakos SA, Dixon JB, Daniels SR, Zeller MH, et al. Long-term outcomes of bariatric surgery in adolescents with severe obesity (FABS-5+): a prospective follow-up analysis. Lancet Diabetes Endocrinol. 2017;5(3):165-173. doi:10.1016/S22138587(16)30315-1. 